\title{
Integration of Universities in the Cluster Structures as a Condition for Economic Development
}

\author{
Yury N. Moseykin \\ Faculty of Economy \\ Peoples' Friendship University of Russia (RUDN \\ University) \\ Moscow, Russian Federation \\ moseykin_yun@rudn.university
}

\author{
Natalia S. Sakharchuk \\ Institute of World Economy and Business \\ Peoples' Friendship University of Russia (RUDN \\ University) \\ Moscow, Russian Federation \\ sakharchuk_ns@rudn.university
}

\begin{abstract}
This paper is about the role of universities in charge of training the highly qualified specialists for the enterprises of the cluster. The integration of multi-level educational institutions will be obtained by the concentration of scientific, educational, teaching and material resources for the development and implementation of an effective education system, which will fully meet the requirements of cluster economy. This is possible only in the implementation of the principle of combining vertical: secondary school - industry specialized educational institutions - university - the enterprise of the cluster. This chain forms the co-creation and co-financing, while familiar to us the interaction of the enterprise and the university for specific conditions - is the focus on the individual educational discipline.
\end{abstract}

Keywords-cluster structure; university; integration; highly qualified specialists; professional knowledge

\section{INTRODUCTION}

The current period is characterized by significant changes in the education system. This is a new concept of social and economic development of the country as a whole and the regions in particular.

Prospects of the development of the modern university are one of the most discussed in the XXI century. This is due to an active and dynamic process of rethinking the essence of higher education - the emergence of new requirements for higher education.

Today the obvious misbalance between the demands for what the university has to "produce" and the offer in terms of technology and the globalization of the economy. There is the evolution in the University that transforms it into the enterprise type system. The University, it becomes a part of the cluster, keeping the characteristic features of a classical university.

The University must respond to the inevitable growing demands of the national economy to the education. The role of the university may become more important in the creation of a marketable product for business - the qualified staff.

\section{MATERIALS AND METHODS}

\section{A. Literature review}

The concept of "cluster" was introduced into widespread use in the late $1980 \mathrm{~s}$, and was expecting a group of

The publication was financially supported by the Ministry of Education and Science of the Russian Federation (the Agreement number 02.a03.0008). geographically adjacent interconnected companies and associated institutions that need to operate in a certain area, characterized by common activities and complements each other.

Alfred Marshall [1] was the first economist who commented the relational communications between companies and entire industries; he also emphasized the agglomeration of individual sectors in some areas of England.

Later, Michael Porter [2] proposed a theory about the importance of creating clusters in economic development, the role of interaction and ideas exchange between companies with ensuring a balance of professional interests, according to this cluster - its geographically concentrated groups of interconnected companies: specialized suppliers, service providers, firms in their respective industries, as well as associated with their activities of organizations (eg, universities, agencies for standardization, as well as trade associations) in certain areas, competing, but at the same time working together.

If in the XX century, clusters specialized in the production of consumer goods in order to increase the competitiveness of the territories, in the XXI century with the advent of a new generation of clusters - they expanded their functionality and structure.

In 2008, European countries have adopted a memorandum of cluster policy, which announced their intention to withdraw their clusters in the global technology leaders [3].

In 2008 in Russia adopted the Concept of long-term socioeconomic development of the Russian Federation, which provides for the creation of a network of territorial and industrial clusters, realizing the competitive potential of the territories, the formation of a number of innovative high-tech clusters in the European and Asian parts of Russia [4].

Cluster is an integrated infrastructure, with geographically concentrated companies, suppliers of basic and support services, financial institutions, industrial structures, as well as specialized agencies (including universities), whose competitive advantages are improved by combining them and provides long-term economic growth and competitiveness of an effective system.

Speaking about the integration of the universities in the cluster structures, we expect the union activities of the 
institution (higher school), businesses, and the public sector that is stakeholders towards achieving competitive advantages, interaction and self-development of a cluster of subjects.

The problem of the cluster approach in the formation of Russian is studied by scientists such as Valeriy Burdakov, Vyacheslav Volov, Tatiana Davydenko, Evgeniy Korchagin, Guzel Mukhametzyanova, Natalia Pugacheva, Peter Tretyakov, Tatiana Shamova and other scientists.

\section{B. Description of the problem}

The main problem of the modern education system is its insufficient with the labor market needs of Russia. The labor market and the education system should be in direct proportion - universities need to produce those professionals who are in demand on the market. Today training in traditional specialties of each institution meets the needs of the population, rather than the national economy. Annually the Russian state and municipal educational institutions of higher education produce bachelors and masters, thus $87 \%$ of the working population of Russia have a profession, confirmed by a diploma or other document (Fig. 1, Table 1).

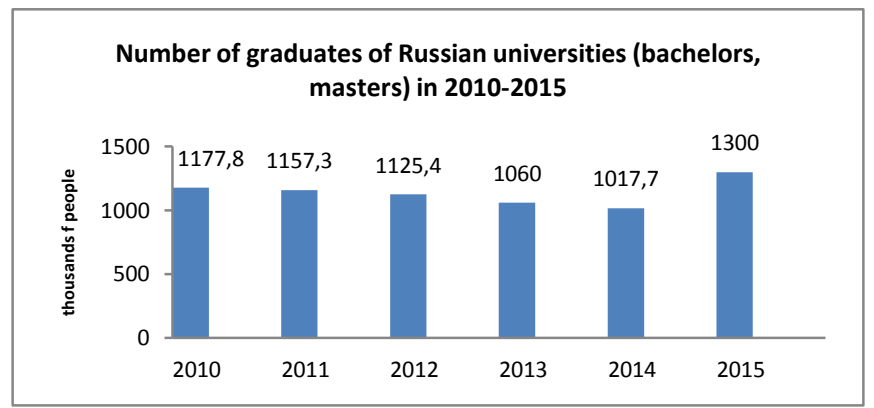

Source: compiled by the author based on statistical collection data "Labor and Employment in Russia - 2015" [5] and information on the official website of the Ministry of Education and Science of the Russian Federation [6]

Fig. 1. Number of graduates of Russian universities (bachelors, masters) in 2010-2015 (thousands of people)

However, almost $60 \%$ of Russians do not work in their specialty [7]. According to the results of monitoring [8] conducted by Russian Ministry of Education, the highest percentage of employment (from 80 to $90 \%$ ) of graduates in the engineering and medical training areas. Among the major specialties and areas on this indicator - nuclear energy and technology, nursing, pharmacy, electrical and heat power engineering, chemical technology. Worst of all employed graduates with a legal and economic education: almost $40 \%$ of lawyers and $20 \%$ of economists and managers do not find themselves in the labor market in the first year after graduation. These graduates of this training area are the most numerous who don't employ by the specialty. Data on employment of Russian youth are shown in Fig. 2

At the same time the unemployment rate remains at a low level and amounts to 3\% [9], but the sectors of the national economy are understaffed (Table 2), which affects the economic development of Russia.

This is primarily due to rupture of the labor market demand (employers), manifested in the orientation of high schools on a request from the students and their parents who are willing to pay money for education that seems to them promising.

TABLE I. RELEASE OF BACHELORS AND MASTERS IN GROUPS OF SPECIALTIES AND AREAS OF TRAINING (THOUSANDS OF PEOPLES)

\begin{tabular}{|c|c|c|c|c|c|}
\hline $\begin{array}{c}\text { Areas of training and specialization / } \\
\text { Year }\end{array}$ & 2010 & 2011 & 2012 & 2013 & 2014 \\
\hline physic-mathematical sciences & 16,5 & 16,5 & 16,6 & 15,7 & 15,4 \\
\hline natural sciences & 16,7 & 16,6 & 16,5 & 16,1 & 17,6 \\
\hline humanitarian sciences & 192,5 & 192,8 & 196,1 & 177,2 & 158,0 \\
\hline social sciences & 18,2 & 18,2 & 16,5 & 15,4 & 16,8 \\
\hline education and pedagogy & 125,5 & 114,4 & 107,0 & 102,6 & 96,9 \\
\hline healthcare & 33,3 & 33,5 & 34,3 & 36,0 & 35,9 \\
\hline culture and art & 19,7 & 20,0 & 19,8 & 20,6 & 20,6 \\
\hline economics and manag & 408,8 & 405,1 & 385,3 & 350,5 & 331,0 \\
\hline information security & 3,6 & 3,7 & 3,8 & 3,4 & 3,5 \\
\hline service sector & 14,5 & 15,8 & 16,5 & 16,2 & 14,7 \\
\hline agriculture and fisheries & 36,7 & 34,9 & 34,3 & 35,2 & 32,1 \\
\hline surveying and land management & 5,7 & 5,9 & 6,7 & 7,0 & 6,4 \\
\hline $\begin{array}{l}\text { geology, exploration and development of } \\
\text { mineral resources }\end{array}$ & 15,4 & 16,4 & 16,8 & 16,8 & 17,5 \\
\hline $\begin{array}{c}\text { energy, power engineering and electrical } \\
\text { engineering }\end{array}$ & 29,4 & 29,7 & 29,4 & 28,0 & 29,3 \\
\hline metallurgy, machine building & 28,4 & 26,6 & 24,2 & 23,1 & 23,3 \\
\hline aviation, rocket and space technology & 5,9 & 5,6 & 5,6 & 5,1 & 5,4 \\
\hline weapons and weapons systems & 0,6 & 0,5 & 0,4 & 0,4 & 0,4 \\
\hline marine engineering & 4,4 & 4,3 & 4,0 & 3,6 & 4,2 \\
\hline transportation & 35,8 & 34,4 & 34,5 & 34,0 & 33,8 \\
\hline instrument and optical engineering & 9,3 & 9,1 & 8,2 & 7,6 & 7,7 \\
\hline $\begin{array}{l}\text { electronic engineering, radio engineering } \\
\text { and communications }\end{array}$ & 18,2 & 17,4 & 16,1 & 15,3 & 15,2 \\
\hline automation and control & 16,6 & 16,4 & 15,9 & 15,8 & 16,5 \\
\hline computer science and engineering & 26,7 & 26,2 & 25,8 & 25,7 & 27,0 \\
\hline chemical and biotechnology & 12,8 & 11,6 & 10,8 & 10,2 & 10,2 \\
\hline $\begin{array}{c}\text { reproduction and processing of forest } \\
\text { resources }\end{array}$ & 6,7 & 6,5 & 6,2 & 6,4 & 5,5 \\
\hline $\begin{array}{l}\text { technology of food products and consumer } \\
\text { goods }\end{array}$ & 19,2 & 18,4 & 16,7 & 15,2 & 16,0 \\
\hline architecture and construction & 43,0 & 43,8 & 43,0 & 42,9 & 43,0 \\
\hline $\begin{array}{l}\text { life safety, environmental engineering and } \\
\text { environmental protection }\end{array}$ & 13,9 & 13,2 & 14,4 & 14,0 & 11,6 \\
\hline
\end{tabular}

In conditions of economic crisis the company different sectors are leads one to think about the optimization management of the human asset.

There is a need for the integration of higher education institutions in the industrial and business environment, forming clusters. Such interaction becomes favorable. Moreover, it is primarily beneficial primarily in terms of improving the competitiveness of products, reduction of production costs, and most importantly there preparation of truly qualified specialists for cluster. The uniqueness of the cluster approach is that a person is immersed in professional field from an early age, gradually acquiring the general and practice-oriented knowledge and by the end of the university specialist has known well enough production and it significantly shortens the time of his entry into the profession. 


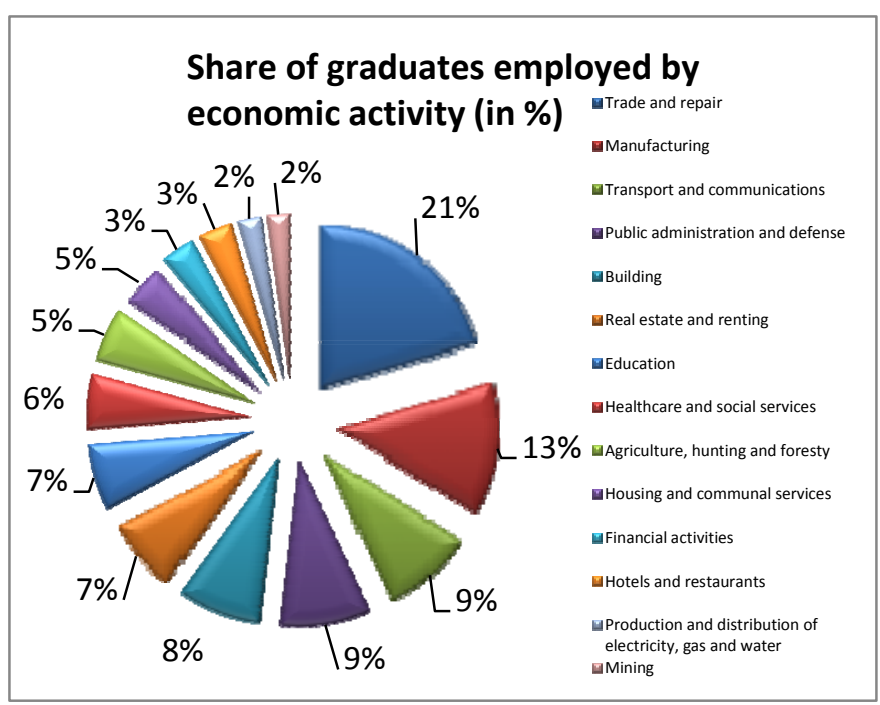

Source: Institute of Psychology of the Russian Academy of Sciences

Fig. 2. Share of graduates employed by economic activity (in \%)

TABLE II. THE NUMBER OF EMPLOYEES REQUIRED FOR VACANCIES BY ECONOMIC ACTIVITY (2014)

\begin{tabular}{|c|c|c|c|c|}
\hline \multirow[t]{2}{*}{ Field of activity } & \multicolumn{2}{|c|}{ Number of persons } & \multicolumn{2}{|c|}{\begin{tabular}{|c|} 
In \% to the \\
payroll number \\
of employees
\end{tabular}} \\
\hline & 2013 & 2014 & 2013 & 2014 \\
\hline Total & 1035305 & 952843 & 3,0 & 2,8 \\
\hline agriculture, hunting and forestry & 30033 & 25412 & 2,6 & 2,3 \\
\hline fishing, fish farming & 766 & 675 & 1,9 & 1,8 \\
\hline mining & 15174 & 12620 & 1,6 & 1,4 \\
\hline manufacturing & 108167 & 97244 & 1,8 & 1,7 \\
\hline $\begin{array}{l}\text { production and distribution of } \\
\text { electricity, gas and water }\end{array}$ & 48143 & 43563 & 2,8 & 2,6 \\
\hline building & 22947 & 21839 & 1,8 & 1,8 \\
\hline $\begin{array}{l}\text { wholesale and retail trade; repair of } \\
\text { motor vehicles, motorcycles, } \\
\text { household goods and personal items }\end{array}$ & 58032 & 50660 & 2,4 & 2,0 \\
\hline hotels and restaurants & 12792 & 13272 & 4,6 & 4,8 \\
\hline transport and communications & 104629 & 101077 & 3,3 & 3,3 \\
\hline financial activities & 35652 & 31356 & 3,1 & 2,7 \\
\hline $\begin{array}{l}\text { real estate, renting and business } \\
\text { activities }\end{array}$ & 106470 & 107694 & 4,1 & 4,0 \\
\hline $\begin{array}{l}\text { public administration and defense; } \\
\text { social insurance }\end{array}$ & 159172 & 159549 & 4,6 & 4,6 \\
\hline education & 73122 & 59785 & 1,4 & 1,1 \\
\hline health care and social services & 222507 & 193457 & 5,2 & 4,5 \\
\hline $\begin{array}{l}\text { other community social and personal } \\
\text { services }\end{array}$ & 37694 & 34634 & 3,2 & 3,0 \\
\hline
\end{tabular}

\section{Methods study}

In the study, the authors used some methods such as a comparative analysis, synthesis, systematic approach and classification, historical method.

\section{RESULTS}

The main objective of the new economic regions is to provide a platform of positive dynamics of economic development with cluster type, investment and priority directions for the modernization of their production, enabling the transition to a qualitatively new stage of development and the formation of post-industrial economy with an increasing share of high-tech sector, the creation of modern innovationdriven energy efficiency and resource industries based on "knowledge economy", producing competitive products that meet international standards, ensuring the growth of labor productivity, supporting the development of innovative infrastructure for technology transfer from science to production.

Programs and projects of the cluster organization of territories may be regarded as a new integrated approach to the modernization of the state of the economy, as it implies the use of natural, historical advantages in deep areas of specialization industries.

In this case, the clusters are integrated not only in the procurement of raw materials, production and processing, but in the scientific and intellectual and social fields.

In modern conditions, the target benchmark program of cluster development is changing focus of the participating companies: from intermediate and raw materials to a producer of a wide range of market demands with innovative products of mass consumption with high added value. However, the necessary and sufficient changes entail appropriate security complex modern production by highly qualified specialists. Consequently, the meaning of universities in charge of their training increases repeatedly.

Integration into common European educational space poses universities management a need to address this urgent task, as the formation of a new type of education based on the cluster approach.

There is no doubt that universities have always been the center of scientific research integration. If the institutes and academies main business was to educate, the "University becomes a Higher education and research institution, which provides the entire set of disciplines that make up the foundations of scientific knowledge." Thus, universities can serve a key part of the cluster, not only in the field of training and research activities, but also in the creation of innovative infrastructure for the transfer of scientific developments.

An important value has the internal interaction between all participants in the cluster, which is through integration segments cluster forms a single economic space. Consequently, the clusters and the education system should be in direct proportion - universities must not only produce those professionals who will be in demand in the labor market, but also to prepare truly qualified personnel to meet the specifics of the cluster. Thus, to strengthen the links of vocational education with the needs of the labor market, as well as formed an opportunity to create a new synergistic quality.

The ability to integrate education cluster structures emphasizes the uniqueness of the cluster approach. Clustering of educational activities will create an opportunity for a person by immersion in professional golf from an early age to purchase general and practice - oriented professional knowledge, and by the end of the profile of the University specialist will have sufficient knowledge of the production, which will significantly reduce the period of his professional adaptation. At the same time, it will improve the quality of training of the cluster and the competitiveness of the young 
specialist. Thus, the integration of the University of the cluster - is the integration of multi-level educational institutions, which would achieve the desired concentration of scientific, educational, teaching and material resources to develop and implement a new system of education. Therefore, special value will represent the thought structure of the cluster, which will include:

- The specialized university, which provides training in accordance with the activity of the cluster.

- The group of multi-level educational institutions (schools, colleges) that train students for the university and research institutes, design bureaus, etc.

- The enterprises of the cluster that require highly qualified personnel (the main industrial enterprise of the territory, medium and small enterprises - manufacturers of components and raw material suppliers).

The essence of education is to bring together clusters headed by a main university, institutions of primary and secondary vocational education, specialized schools, basic enterprises - the main customers and consumers of specialists.

That is why the questions about training and retraining should be resolved exclusively within the cluster. If the clusters and the education system will work closely, being directly dependent - universities will produce professionals who are really in demand in the labor market - will form the opportunity to create a system of affordable and continuing professional education, capable of supporting the competitiveness of the cluster.

\section{DISCUSSION}

Our research is actual not only at the national level for policy formation in the relevant area, but also for companies who want to attract the best staff to grow their business and create competitive conditions of their work.

A set of specific recommendations for the key sectors of the necessary labor force, taking into account the priority use of local and national labor force would address not only the understaffed and improve the mechanism of interaction between public authorities, industry and business, scientific and academic environment.

Moreover, the study examined the existing scientific and theoretical approaches to define and identify the nature of the cluster.

The cluster approach is used in all the leading countries of the world. Experience confirms that the creation of clusters - an effective tool.

In this paper, the authors identified and structured the main elements of the educational cluster, offered the essence of the concept.

In our opinion, the integration of universities in the cluster structures requires a number of prerequisites:

- Set of educational institutions that interact within the educational space using competitive advantages territory.
- A leader who defines a long-term innovative and other strategy of the entire system of educational institutions.

- Educational resources (defined as the totality of human resources, legal, informative, financial and logistical resources to obtain the final product of the education system, which is a human representation of the structure of society, its set of characteristics that defines demo culture of region as part of the social component of its development, including mentality).

- Standards that ensure the implementation of requirements for the level of education and competence of those professionals who will be involved in the solution of problems of clusters development.

- Research organizations improve the skill level of employees of educational institutions that will lead to domestic and foreign competition agencies.

- An atmosphere of trust and creativity is a consequence of the mutual advantages enjoyed by the educational institution located in the same area.

\section{CONCLUSION}

Thus, the value of the university is primarily ensuring cluster members not only innovation, but also professionals, providing continuous innovation process, and this is possible only with implementation of a principle of combining vertical: secondary school - industry specialized educational institutions - university - the enterprise of the cluster. This chain forms a co-partnership, co-creation and co-financing, whereas the familiar to us interaction between the enterprise and university within specific conditions - is focusing on the individual educational discipline.

All this will form a common educational space and create the most favorable conditions for the preparation of highly qualified professionals who will fully meet the requirements of cluster economy.

\section{REFERENCES}

[1] Marshall Alfred, Principles of Economics, 1890 http://www.econlib.org/library/Marshall/marP.html

[2] Porter Michael, Competition. Williams, 2005, pp. 28-29.

[3] OECD Reviews of Regional Innovation, 2007.

[4] The concept of long-term socio-economic development of the Russian Federation, 2008.

[5] Statistical collection data "Labor and Employment in Russia - 2015"http://www.gks.ru/bgd/regl/b15_36/Main.htm

[6] Information on the official website of the Ministry of Education and Science of the Russian Federation - http://минобрнауки.рф

[7] Marina Gusenko. In the trend is only doctors / / Rossiyskaya Gazeta Federal issue №6992 (124), 08. 06. 2016 https://rg.ru/2016/06/08/nazvana-samaia-vostrebovannaia-professiia-vrossii .html

[8] The results of the second monitoring of the employment of graduates. June 20, 2016 - http: //mininobrnauka.rf/news/8441

[9] The employment rate and the level of unemployment by educational level: 2014. Indicators of education, 2016, pp. 48 